Document downloaded from:

http://hdl.handle.net/10251/40222

This paper must be cited as:

Lerma Elvira, N.; Paredes Arquiola, J.; Andreu Älvarez, J.; Solera Solera, A. (2013). Development of operating rules for a complex multireservoir system by coupling genetic algorithms and network optimization. Hydrological Sciences Journal. 58(4):797-812. doi:10.1080/02626667.2013.779777.

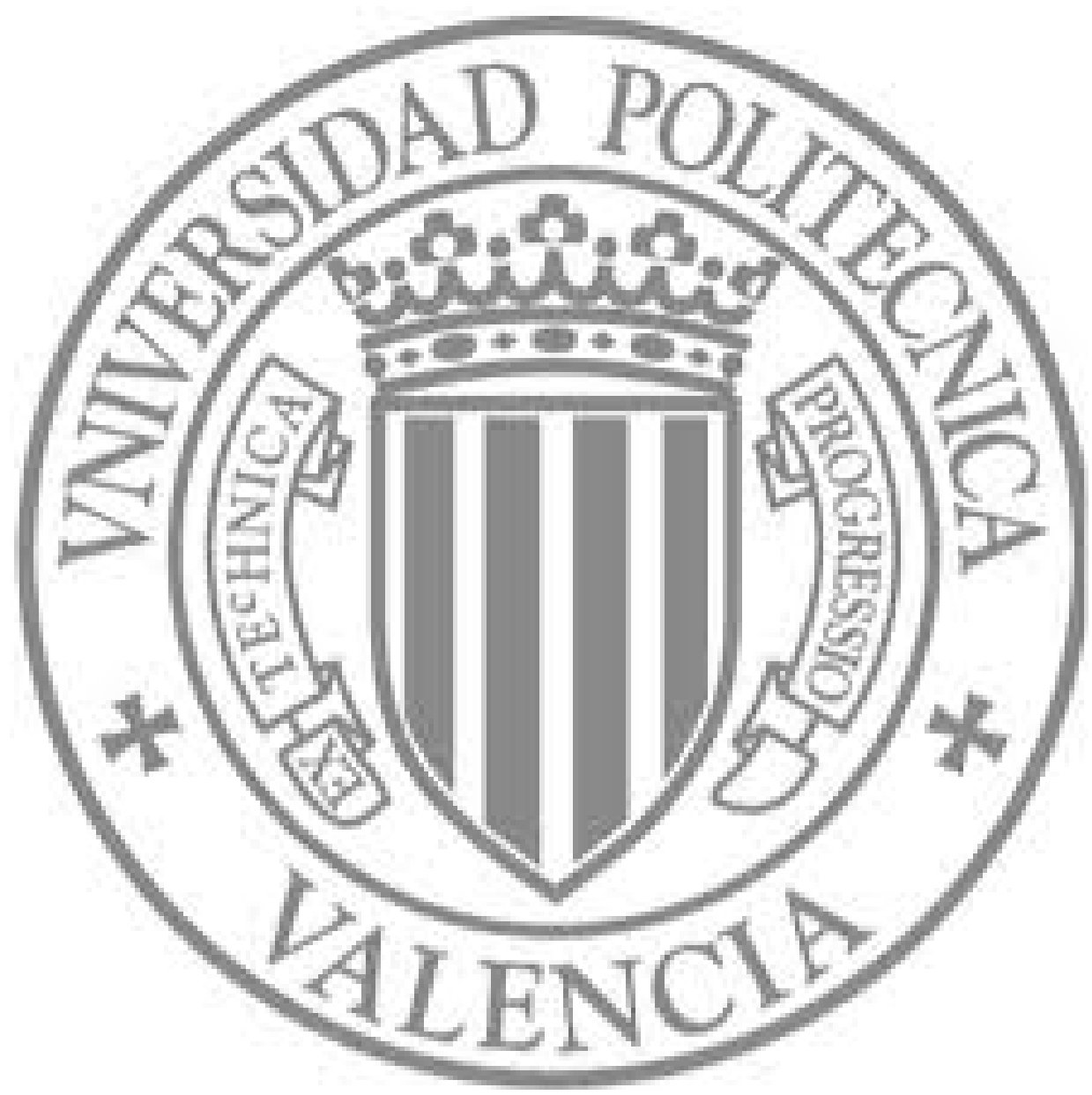

The final publication is available at

http://dx.doi.org/10.1080/02626667.2013.779777

Copyright Taylor \& Francis; STM, Behavioural Science and Public Health Titles 


\title{
Development of operating rules for a complex multireservoir system by coupling genetic algorithms and network optimisation.
}

\author{
N. Lerma, J. Paredes-Arquiola, J. Andreu, and A. Solera. \\ Instituto de Ingeniería del Agua y Medio Ambiente. Universitat Politècnica de València. Caminos de \\ Vera s/n. 46022, Valencia. Spain. \\ Email: neslerel@upv.es
}

\begin{abstract}
An alternative procedure for assessment of Operation Rules (ORs) under drought situations is proposed in this paper. The definition of ORs for multireservoir water resources systems (WRSs) is a topic that has been widely studied by means of optimisation and simulation techniques. A traditional approach is to link optimisation methods with simulation models. The objective of this paper is to obtain drought ORs for a real and complex WRS: the Júcar River basin in Spain. One of the main issues in this basin is the resource allocation among agricultural demands in periods of drought. To deal with this problem we present a method based on the combined use of Genetic Algorithms (GA) and Network Flow Optimisation (NFO). The GA used was PIKAIA, which has previously been used in other water resources related fields. This algorithm was linked to the SIMGES simulation model, a part of the AQUATOOL Decision Support System (DSS). Several tests were developed for defining the parameters of the GA. The optimisation of various ORs was analysed with the objective of minimising short-term and long-term water deficits. Results show that simple ORs produce similar results than more sophisticated ones. This paper demonstrates the usefulness of this approach in the assessment of ORs for complex multireservoir systems.
\end{abstract}

Key words water resources system, genetic algorithms, Pikaia, operating rules, decision support system, Aquatool, simulation, optimisation, agricultural demands, drought, deficits

Développement de règles de fonctionnement d'un système complexe multi-réservoirs par couplage d'algorithmes génétiques et d'une optimisation en réseau

\section{Résumé}

Une méthode alternative pour l'évaluation des règles de fonctionnement (ORs) dans des situations de sécheresse est proposée dans cet article. La définition des ORs pour des systèmes multi-réservoirs de ressources en eau (WRSs) est un topique qui a largement été étudié par le moyen de techniques d'optimisation et de simulation. L'approche traditionnelle est de relier les méthodes d'optimisation avec les modèles de simulation. L'objectif de cet article est d'obtenir les ORs de sécheresse pour un WRS réel et complexe : le bassin de la rivière Jucar en Espagne. L'une des problématiques principales de ce bassin est la répartition des ressources entre les différents besoins agricoles en période de sécheresse. Pour faire face à ce problème, une méthode basée sur l'utilisation combinée d'algorithmes génétiques (GA) et optimisation de réseaux de flux (NFO) est présentée. L'algorithme génétique utilisé est Pikaia, qui a déjà été employé dans d'autres domaines liés aux ressources en eau. Cet algorithme a été introduit par exemple dans le modèle de simulation SIMGES, qui est un module du système d'aide à la décision AQUATOOL (DSS). Plusieurs tests ont été développés pour définir les paramètres du GA. Les optimisations de différents ORs ont été analysées dans le but de minimiser les déficits en eau à court et à long terme. Les résultats montrent que les ORs simples produisent des résultats semblables aux ORs plus sophistiqués. Cet article démontre l'utilité de cette approche dans l'évaluation des ORs pour les systèmes complexes multi-réservoirs.

Mots clés : système de ressources en eau, algorithme génétique, Pikaia, règles de fonctionnement, système d'aide à la décision, Aquatool, simulation, optimisation, besoins agricoles, sécheresse, déficits. 


\section{INTRODUCTION}

Several authors have noted the lack of application of optimisation models to the practical management of multireservoir WRSs (Yeh 1985, Wurbs 1993, Labadie 2004). One of the main reasons for this shortcoming is the necessarily high degree of simplification of these models that removes them excessively far from reality, with the result that water managers lack sufficient confidence in their results to base decisions on model prescriptions. Nevertheless, Oliveira and Loucks (1997) argue that this fact is more likely due to institutional limitations than to technological or mathematical difficulties.

As pointed out by Yeh (1985), there is no general method for optimising reservoir operations; it ranges from simulation to optimization models. Typical methods of optimising reservoir operations are: Linear Programming, Heuristic Approaches, Stochastic Dynamic Programming methods (Mousavi 2004, Celeste and Billib 2009, Tilmanta 2002), Evolutionary Optimisation (Oliveira and Loucks 1997) and other approaches. These methods, used in optimal control of reservoir systems, require a large number of control variables, which are typically the sequences of releases from all reservoirs and for all time steps of the control period (Koutsoyiannis and Economou 2003).

Simulation models are generally preferred instead of typical optimisation schemes (such as linear, dynamic or stochastic dynamic programming models); the latter suffer both, from the high dimensionality, and the exaggerated and often unrealistic simplifications that are unavoidably made, concerning the operation of the real-world system (Efstratiadis et al. 2004). Simulation models allow for a more detailed representation of the system than optimisation models (Loucks and Sigvaldason 1982). Thus, in general, river basin management is performed with the support of simulation models that are characterised by their flexibility and capacity for representing very complex elements. However, these models require the establishment of predetermined ORs or a definition of system management.

The design of Operating Rules (ORs) for multireservoir systems is a topic that has been studied deeply in the history of water resources management. ORs can be obtained from the results of optimisation models using linear regression (Young 1967), multiple linear regression (Bhaskar and Withlach 1980) and the use of simple statistics or tables and diagrams (Lund and Ferreira 1996). Unfortunately, regression analysis may yield poor correlation results, invalidating the ORs so obtained (Labadie 2004).

It is desirable to use a modelling approach combining adherence and flexibility of simulation models with the efficient exploration of mathematical optimization models (Wurbs 1993). Labadie (2004) and Rani and Moreira (2010) reviewed the state-of-theart regarding the optimization techniques used for multi-reservoir systems, which represent the majority of water allocation problems. Both authors said that the most favored technique for water allocation models has been linear programming. This technique is the most traditional (ReVelle 1999) and has been used for optimizing 
resources management of whole river basin schemes (Zoltay et al. 2010), developing decision support systems for urban water supply areas (Yamout and El-Fadel 2005), and optimizing irrigation water allocation in complex agricultural schemes (Reca et al. 2001a, b). Network flow programming is a computationally efficient form of linear programming and, as was shown by Kuczera (1989) and Kuczera (1993), is more suitable than linear programming for solving large multi-reservoir multi-period models.

Moreover, the combination of nonlinear algorithms with linear or network flow programming is a specific and very efficient in water resources models. For example, Cai et al. (2001) described strategies for solving large nonlinear water resource management models combining GA with linear programming, in which a GA/LP approach was applied to a reservoir operation model with a nonlinear hydropower generation and to a long-term dynamic river basin planning model. Another methodology was proposed by Nalbantis and Koutsoyiannis (1997) introducing a parametric rule based in two parameters per reservoir. They proposed and tested a multireservoir parametric rule where parameters are estimated by means of linear and nonlinear optimization methods, using simulation to evaluate the objective function for each trial set of parameter values. The advantage of this approach is the parsimonious formulation with just two parameters per reservoir making searching most effective than other optimisation approaches. Efstratiadis et al. (2004) make use of the aforementioned operation rules to represent the system parameterization, an NFP method to solve the simulation problem and an evolutionary algorithm to determine the optimal parameters.

However, even with these methodologies, and despite potential for the use of optimization in the search for efficient alternatives, full integration between simulation and optimization has not yet been achieved to close the gap between research and realworld application .

Although various strategies have been defined for using optimization and simulation techniques in combination, few of these have been employed in real-world multireservoir and multiuse water systems (Sechhi et al. 2009). In many real water systems, especially systems affected by droughts, managers employ OR based on taking decisions depending on the storage of the system and/or last inflows. The decisions are normally related to reduction of the demand or increment of the resource. In particular ORs for drought mitigation are developed defining some thresholds values (Rossi et al. 2011). These ORs can be considered Trigger ORs (TORs) because one or several actions are triggered when the system reaches a specific situation. Although some authors have criticised the use of this kind of ORs because of their relative inefficiency (Karamouz et al. 2000), the practical management of systems is usually performed with these kinds of rules due to their ease of application and comprehension. Additionally, there are several aspects of these curves that give them special relevance. First, a great number of multireservoir systems are managed by the division of reservoirs into layers (Pool-Based Rule systems). For example, many of the reservoirs built by the US Corp of Engineers are managed on the basis of defined layers or storage zones divided by 
reservoir curves (Lund and Ferreira 1996). Moreover, TORs have other advantages: they are easy to understand for both users and basin managers, they can be implemented into a legal framework, and they are extremely useful as triggers for decision making during periods of drought. Typically, these decisions concern restrictions on transfers, restrictions on nonpriority demands, and the initiation of special measures such as drought wells. Historically, these curves have been widely used in WRS planning and management.

A typical technique for obtaining TORs is the iteration with basin simulation models. These iterations can be controlled by an optimisation algorithm that varies the ORs according to the results of the simulation model runs. Among the possible optimisation algorithms than can be used, Genetic Algorithms (GAs) are characterised by their flexibility for adaptation to any kind of problem and by avoiding local optima better than gradient methods. Nicklow et al. (2010) recently reviewed the state of the art of GAs and evolutionary techniques applied to water resource planning and management. In the particular case of ORs, Oliveira and Loucks (1997), and later Ahmed and Sarma (2005), presented an approach for optimising ORs for multireservoir systems using GAs. Among recent application cases, Chen et al. (2007) applied a multiobjective GA to optimise the rule curves of a multipurpose reservoir system in Taiwan; Elferchichi et al. (2009) also applied a real-coded GA to optimise the operation of reservoirs in an ondemand irrigation system, and this was later applied to the Sinista Ofanto irrigation scheme (Foggia, Italy).

In this paper we propose a methodology for obtaining TORs for a real and very complex WRS. The novelty of the approach resides in the combination of short term and long term reliability and vulnerability indicators in a multiobjective function for the definition of the parameters of a TOR. The engineering interest is demonstrating that the coupled simulation optimization model based on SIMGES and a GA (PIKAIA) is able to solve the problem in a robust way for complex real cases. This methodology is applied to the Júcar River basin in Spain. This basin is a complex system with intensive use of its resources, principally for irrigation demands, although other uses such as hydropower production and urban supply were also considered. To deal with this problem we present a method for the development of TORs for multireservoir systems by coupling GA with Network Flow optimization (NFO) basin simulation models.

\section{METHODOLOGY}

Analysis of reservoirs management under drought conditions has received increasing attention in the last years, specially the optimization of the rule curves and the operational procedures (Hsu et al. 2004, Chang et al. 2005, Cañon et al. 2009). Reservoir ORs under drought conditions are based on proactive measures, to be adopted before drought impacts occur (Rossi et al. 2011). 
The proposed methodology, depicted in Figure 1, is based on the estimation of TORs of the rule curve type for a complex multireservoir system with a basin simulation model through an iterative process. The optimisation search model used is PIKAIA (Charbonneau and Knapp 1995), a flexible and easy-to-use GA. For the evaluation of the objective function (OF), a basin management simulation model is required. This model represents the system situation in a proposed operational mode. The basin simulation model was developed with the SIMGES program (Andreu et al. 1996), which is part of the AQUATOOL DSS (Andreu et al. 1996). In the following, the characteristics of the optimisation algorithm, the simulation model and the coupling method are briefly explained.

\subsection{Trigger Operation Rules}

Generally ORs are a set of guidelines to define releases from the reservoir that serves as a protocol for the operators. The difference between operation rules that are prespecified and rules that are determined through optimization is that this are typically characterised as parametric, given that their parameters are handled as control variables to an optimization problem. There are many types from simple to very complex and usually relate outflows from reservoir with the storages volume and/or past or future hydrological variables. Among the best known are the Rule curves specifying the target storage at the end of each month. These rules have been widely used in practice for its simplicity. Different adaptations of ORs Curves, as parametric, have been developed and its usefulness has been tested (Koutsoyiannis and Economou 2003).

Other ORs related to Rule Curves, but where the curve is not a goal to be achieved but a threshold at which a decision is made are, as defined previously, TOR. These types of ORs are formed by a curve of an indicator and an action. The indicator can be the storage in one or more reservoirs, the inflows of last months in a system or the level of an aquifer. The action is related to a decision to be made that affects water supply of demands or alternative resources. This type of operation rules are applied in situations of drought in real systems. For example, in Spain, in the development of the Drought Special Plans (GPEASAS 2005) many systems based their Plans in defining this kind of ORs.

\subsection{The PIKAIA algorithm}

PIKAIA is a GA that, as all GA, is based on the search for an optimum using Darwinian evolutionary theory. Although its application has been more frequent in astrophysics, it has also been used in the calibration of water quality parameters with the QUAL2K model (Pelletier et al. 2006). The algorithm is based on six steps: initial population generation, fitness evaluation, selection, crossover, mutation, replacement and evaluation. It has two basic genetic operators: uniform crossover and mutation.

PIKAIA is based on a decimal codification as other GA packages, for example GENOCOP or GEATbx. There are three reproduction plans: complete generational 
replacement, random elimination and worst individual elimination. Elitism is also available and is a default option.

The mutation rate can be dynamically controlled by modifying the aptitude difference between the best individuals and the median of the population (also a default option). Selection is based on stochastic sample selection and individual arrangement, making use of the roulette-wheel algorithm (the probability of choosing an individual is proportional to its aptitude). The mutation modes implemented in PIKAIA are one-point mutation with: fixed rate, adjustable rate based on fitness, or an adjustable rate based on distance. PIKAIA has been used the version adapted for Microsoft Excel by Pelletier et al. (2006).

\subsection{The SIMGES simulation model}

The proposed method requires multiple iterations of a representative simulation model of the studied WRS. For this purpose, we used SIMGES module of the DSS AQUATOOL. Both, the simulation module and the DSS, have been widely applied to river basins in Spain and abroad (CHJ 1998, MIMAM 2000, DICTUC 2010, UNICA 2012, Jamieson 1997). SIMGES model is based on the conceptualization of a river basin as a set of interconnected elements that represent the real components of the WRS and their interactions. A large variety of elements is available, as reservoirs, river reaches, channels, aquifers, hydroelectricity generation facilities, groundwater pumping facilities, return flows, demands and intakes, etc.

In the simulation process, for every time step (one month in this case) SIMGES model translates different water resources elements such as inflows, demands, rivers, reservoirs, into a Network Flow Optimization (NFO) problem. The NFO is composed by arcs and nodes where each arc is defined by a maximum, a minimum, and a flow cost. The minimum value is zero where using the Out of Kilter algorithm (Ford and Fulkerson 1962). The consideration of the different elements of the system is achieved by means of artificial arcs and nodes. For example environmental, for minimum flows, are considered two virtual arcs one having the capacity equal to the desirable environmental flow and a negative cost and the other without cost and a high upper limit.

The arcs are defined by their initial and final nodes, the maximum and minimum flows passing through them, and the cost of circulating a single unit of flow. In this case, costs are not real costs, but pseudo-costs designed to reflect priorities, physical infeasibilities, preferences, etc. This problem is expressed mathematically as follows:

$$
\operatorname{Min} \sum_{i=1}^{m} \sum_{j=1}^{m} c_{i j} x_{i j}
$$

Subject to: 


$$
\begin{aligned}
& \sum_{j=1}^{m} x_{i j}-\sum_{k=1}^{m} x_{k i}=0 \quad \forall i=1, \ldots, m \\
& x_{i j} \geq l_{i j} \quad \forall i=1, \ldots, m \quad \forall j=1, \ldots, m \\
& x_{i j} \leq u_{i j} \quad \forall i=1, \ldots, m \quad \forall j=1, \ldots, m
\end{aligned}
$$

where $x_{i j}$ is the flow circulating through the arc from node $i$ to node $j, c_{i j}$ is the cost for each circulated flow unit, and $l_{i j}$ and $u_{i j}$ are the lower and upper flow limits, respectively, of the arc starting at node $i$ and ending at node $j$. Actually, the model allows flows lower than the minimum flow limit but does not allow flows greater than the maximum limit. Under these assumptions, the optimisation problem can be efficiently solved using the Out-of-Kilter algorithm (Ford and Fulkerson 1962).

Although the pure mathematical form is the one presented previously, the setting of the arcs, nodes and costs makes that the practical objective function of the model is composed by different terms, one for each element of the system. Depending on the type of element, its contribution to the objective function is different. The equivalent objective function defined in SIMGES model and simplified for reservoirs and demands is the following:

$$
\begin{aligned}
\text { Min } F=\sum_{i=1}^{I}\left(\sum_{n=1}^{m}\left(V_{n, i}\left(C_{n}+p n_{i}\right)\right)+\left(S p_{i} C_{s p}\right)\right)+\sum_{j=1}^{J} D R_{j}\left(C_{d r}+p n_{j}\right) \\
+\sum_{k=1}^{K} D D_{k}\left(C_{D D}+p n_{k}\right)
\end{aligned}
$$

Where $I$ is the total number of reservoirs in the model; $V_{n, \mathrm{i}}$ is the volume of the reservoir $i$ in the pool $n ; m$ is the number of pools in a reservoir; $\mathrm{C}_{\mathrm{n}}$ is the cost/benefit of storage water into the pool $\mathrm{n} ; \mathrm{pn}_{\mathrm{i}}$ is the priority number assigned to the reservoir $\mathrm{I} ; \mathrm{Sp}_{\mathrm{i}}$ is the spill of the reservoir $\mathrm{I}$; and $\mathrm{C}_{\mathrm{sp}}$ is the cost of spills in the reservoirs; $\mathrm{J}$ is the total number of conduits (either river reaches, or channels, or pipes) in the model; $\mathrm{DR}_{\mathrm{j}}$ is the Deficit of the minimum flow established for conduit $\mathrm{j} ; \mathrm{C}_{\mathrm{dr}}$ is the cost of deficit of a minimum flow; $\mathrm{pn}_{\mathrm{j}}$ is the priority number of the conduit $\mathrm{j}$; $\mathrm{K}$ is the number of demands in the model; $\mathrm{DD}_{\mathrm{k}}$ is the deficit of a demand $\mathrm{k} ; \mathrm{C}_{\mathrm{DD}}$ is the cost associated to deficits of demands and $\mathrm{pn}_{\mathrm{k}}$ is the priority number of demand $\mathrm{k}$.

As it can be seen, the above equation is comprised of costs and priorities. The costs, set by default and previously calibrated, allow for the rational behaviour of the model between different types of items: for example supplying water to demands before storing in the reservoirs. Although this "rational behaviour" usually is not changed, a user can modify it altering these costs. On the other hand, priorities also set behaviour between elements of the same type. For example, the priorities identified in the demands establish the order of supplying demands. Priorities between environmental flows and between hydroelectric plants also have to be set. The same system of 
priorities combined with a definition of pools or zones is used for reservoirs. In each reservoir different pools have to be defined and a priority. Releases start from the reservoirs of less priority and all reservoirs are maintained in the same zone whenever possible.

Along with the pools and priority system, the management of reservoirs is defined with ORs. In SIMGES there are ORs that allow modelling decision making based on indicators, as TORs defined previously. Some examples of indicators are the stored volume in one or more reservoirs and the accumulated in stream flow during various months at one or more points of the system. The resulting decisions include the restriction to a certain percentage of one or more demands, turbine flow, environmental flow or pumping from an aquifer. Environmental aspects are also considered in the form of ecological flows to be satisfied.

An important feature of SIMGES is the joint consideration of surface water and groundwater. The program allows to model different types of aquifers and surface and ground connections. Among the models that can be used to represent aquifers are: deposit or reservoir, single cell with discharge through spring, aquifer hydraulically connected to a surface stream, connected to two surface streams, and also distributed heterogeneous aquifer of irregular shape (Andreu and Sahuquillo 1987).

It has to be noticed that the NFO, as formulated above, is used every time step (i.e., one month in the case study) as a mechanism to find a set of flows through the system, storage in reservoirs, and water assignment to demands that fulfils the physical restrictions and fits as best as possible to the ORs and priorities. Therefore, SIMGES is not an optimization model, but rather a simulation model that uses NFO every time step for the mentioned purpose. In fact, NFO has to be solved several times in every time step (i.e., month) in order to deal with nonlinearities in some processes (e.g., evaporation from reservoirs), aquifer simulation (which is made apart, after each NFO optimization), and the resulting surface-groundwater interaction.

\subsection{Simulation and Optimization Models coupling}

The methodology used is based on the construction of an optimisation model with the following characteristics: the Objective Function (OF) considers the short-term and long term deficits of the demands:

$$
f(x)=w_{1} \text { MaxShortTermDe } f_{t}+w_{2} \text { MaxLongTermDe } f_{t}
$$

Where MaxShortTermDef $f_{t}$ represents the maximum annual deficit of several demands,

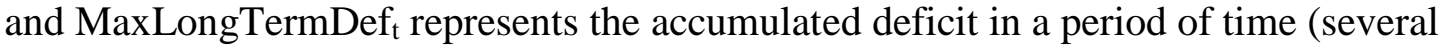
years, 10 years in the case of study). Both terms are weighted by $\mathrm{w}_{1}$ and $\mathrm{w}_{2}$ to incorporate the importance of each concept.

As illustrated schematically in Figure 1, in the PIKAIA optimisation model, each individual operating condition consists of a proposed TOR and a restriction coefficient, and each evaluation of the OF requires a run of the basin management simulation model 
with that TOR. The simulation model estimates, among other things, the deficit in demands due to the proposed TOR. The results files with the series of deficits are then read to calculate the OF that is included into the optimisation model.

\section{THE JÚCAR RIVER BASIN.}

The Júcar River basin is located at the eastern end of the Iberian Peninsula (Figure 2). It covers an area of $22,378 \mathrm{~km}^{2}$, and the length of the main stream is almost $550 \mathrm{~km}$. Its management is complex due to the high degree of use of its resources. The average basin precipitation of $510 \mathrm{~mm} /$ year implies a water resources average of 1,200 $\mathrm{hm}^{3} /$ year including surface water and groundwater. Agriculture is the major water consumption demand, at 1,000 $\mathrm{hm}^{3} /$ year, mainly between April and September. The storage capacity is $2,000 \mathrm{hm}^{3}$. Although the average values may indicate that its resources are sufficient, the Mediterranean climatology, with a strong winter-summer gradient and series of dry years between wet periods, causes the system to suffer frequent over-annual droughts.

The topology of the system is illustrated in Figure 3, which shows the main elements located along the Júcar River itself and its main tributary, the Cabriel River; these include the principal reservoirs, the demands and other elements. The demands can be classified by their supply source into surface, groundwater, and mixed supplies. The majority of the demand is for irrigation, although there are some important urban demands. The agricultural demands are shown in Figure 4.

The practical management of the system depends on the negotiations occurring in the meetings of the "Comisiones de Desembalse" (Reservoir Withdrawal Commission, RWC). Currently, there are no defined ORs. These are meetings among basin agency technicians, users and other stakeholders at different times of the year (almost monthly frequency). The most important one occurs in April, when the water assignments for the irrigation demands are defined for the rest of the hydrologic year. The assignments are defined according to the system state, although there are a series of principles that must be maintained:

- Water storage is preferably performed first in Alarcón, then in Contreras, and finally in Tous. In this way, the upstream storage priority is held above the downstream as long as the probability of spills from the Alarcón reservoir is minimal. Moreover, the Contreras reservoir suffers from a high filtration rate to the underlying aquifer.

- Although all agricultural demands face supply restrictions during droughts, the priority for surface water supply of traditional demands over mixed demands is taken into account. The demands for the Ribera Alta, the Ribera Baja and the Mancha Aquifer are considered to have a higher priority than the demands from the Júcar-Turia Canal Irrigation system and part of the mixed irrigation schemes from the Mancha Aquifer. Conjunctive use of surface and groundwater is performed with intensities depending on the surface water reserves. 
- Environmental flows have been defined at several points along the basin. By law, these must be maintained at all times, except when the drinking water supply is threatened.

The model developed for the Júcar River represents the current situation of the system and simplifies some aspects that did not affect the objective of this study. Six inflows elements were considered, for which the values were obtained by naturalised streamflows. Even though the available series covers the period from 1940 to 2008, only the period corresponding to the last 28 years was used because the longest periods of drought were concentrated in this time, allowing the running time to be reduced without loss of validity.

Also, only the four most important reservoirs were taken into account (Alarcón, Contreras, Tous and Bellús). None of the other existing reservoirs were considered, as they do not play any role in the regulation of the system and are only used for hydropower production. The demands were aggregated to a level sufficient to represent each different irrigation scheme. In the system schema we identified nine aggregated demands: four urban demands (Valencia, Sagunto, Albacete and the Manchuela) and five agricultural demands (Ribera Alta, Ribera Baja, La Mancha Oriental, the JúcarTuria Canal,). Among the aquifers existing in the basin, the La Mancha Oriental (MO) aquifer was considered (another aquifer was introduced to take into account the groundwater infiltration at the Contreras reservoir). MO aquifer is important because the demands from La Mancha are mainly supplied from it, and because there is a very strong relationship with the Jucar river, affecting the flows in the river. SIMGES includes a broad spectrum of approaches for modelling groundwater: reservoir type, aquifer with discharge through spring, aquifer hydraulically connected to a surface stream, connected to two streams and a distributed model. The aquifer model approaches are documented in the user-manual (Andreu et al. 1996). In the NFO after initial values for the decisions are obtained by the optimization algorithm simulations of aquifers are performed and this gives values for the surface-water groundwater relationships which are updated within the networks (Andreu et al. 1996).

Environmental flows defined at several points along the basin were considered in the model by placing them and certain streams of the Júcar River, with flows ranging from 0.5 to $6 \mathrm{~m}^{3} / \mathrm{s}$ (1.3 to $15.3 \mathrm{hm}^{3} /$ month).

\subsection{Specific methodology for the Júcar basin}

The OF that is defined for Júcar Basin is an adaptation of equation (1) and is as follows:

$f(x)=w_{1} \frac{\operatorname{Max}\left(\operatorname{Def}_{1, T r d}\right)-50}{50}+w_{2} \frac{\operatorname{Max}\left(\operatorname{Def}_{10, T r d}\right)-100}{100}+w_{3} \frac{\left(\sum_{t=1}^{n} V_{t}\right)-n * 2000}{n * 2000}$

The first two terms, as discussed in section 2.4 correspond to the deficit in the short and long term, respectively. In the Spanish Hydrologic Planning Instruction (IPH 2008) maximum deficit of one year as short-term deficit and the 10 consecutive years as longterm deficit are commonly used. 
The $\mathrm{w}_{1}$ and $\mathrm{w}_{2}$ represent the selected weights associated with the maximum deficits for one and 10 consecutive years, summing to one. $\operatorname{Max}\left(\operatorname{Def}_{1, T r d}\right)$ represents the maximum deficit in one year for all the traditional demands as a percentage of the whole demand. $\operatorname{Max}\left(\operatorname{Def}_{10, T r d}\right)$ represents the maximum deficit for 10 consecutive years of all the traditional demands as a percentage of the annual demand. It has to be noted that in equation (5), and also in the rest of the paper, all deficits are expressed in terms of percentage of a value equal to the annual demand.

The values of $50 \%$ and $100 \%$ were included in the function used for the reliability criteria as they are the limits established by the IPH-2008 for agricultural demand satisfaction criteria. Therefore, in Spanish law the reliability criteria for agricultural demand was defined so that a demand is satisfied when the maximum annual deficit is less than $50 \%$ of the annual demand, the maximum consecutive two-year deficit is below $75 \%$ of the annual demand, and the maximum consecutive ten-year deficit is below $100 \%$ of the annual demand. The expected results will be negative values as long as the desired deficits are lower than 50 and $100 \%$.

The last term in equation (5) is added to ensure that the algorithm searches the minimum reservoir volume among different possibilities. The factor $w_{3}$ is the weight associated with this term, and here, its value was fixed at 0.01 , a sufficiently low value to ensure that deficits are always more important. The rest of the term is the sum of the volumes in the different months that are considered to be decision variables; this value is reduced by the number of months multiplied by 2,000 (considered the upper volume limit). Similarly to the deficits, the term is divided by the number of months multiplied by 2,000 for a standardized result.

The mixed demand deficits do not appear in the OF because it is assumed that the restriction coefficient for these demands with respect to surface water supply is twice that of the traditional demands. This is an established factor traditionally applied in Júcar River management and accepted by all stakeholders, since they can resource to groundwater. The weights chosen for the OF were $\mathrm{w}_{1}=0.667$ and $\mathrm{w}_{2}=0.333$. The reason to choose these particular values was the desire to diminish large annual deficits and so avoid damage to the agricultural areas due to drought. Even so, a series of preliminary simulations was performed, and the results obtained for different weight values were the same or similar than those for the values finally chosen.

The decision variables for the optimisation problem are the sum of the volumes of the three reservoirs (Alarcón, Contreras and Tous) and a restriction coefficient for the demands. The volume of water stored in the three reservoirs indicates the water reserve for scarcity periods. The upper limit of this variable is considered to be $2000 \mathrm{hm}^{3}$ and the lower $75 \mathrm{hm}^{3}$ due to dead and environmental volume. On the demand side, the restriction coefficient is applied to the traditional demands, multiplying it by two for the mixed demand as explained above. The value of this coefficient ranges between zero and unity. 


\section{SELECTION OF PARAMETERS FOR THE GA}

A characteristic of GA is that there are several options available to define the search process. This section describes the results of the various tests performed on the PIKAIA algorithm that permitted the definition of the best parameters for the TORs. The studied parameters were the initial population, the number of digits of codification, the mutation method, the crossover probability, the elitism and the number of individuals.

As discussed below, there are several possibilities for proposing TORs depending on when each decision is made and for how long that decision is applied. The rule known as "Decision making from April until September" was chosen for analysing the GA parameter selection, as it is the most similar to the actual basin management process.

Figure $5(\mathrm{a}-\mathrm{f})$ represents the $\mathrm{OF}$ (in positive values) obtained by the best individual in each generation of the different tests conducted. The results of the tests performed with different initial population (Figure 5-a) reflect that the first three initial population obtained an optimum before or near generation 30, whereas the last three initial population obtained it by the last generation. Even so, it is apparent that all initial population yielded almost the same results by generation 30 . The analysis of the number of digits considered in the parameter codification, with results depicted in Figure 5-b, revealed that the use of only one or two digits did not yield acceptable solutions compared to the other options. Therefore, we concluded that a minimum of three digits is necessary to provide good results. As the use of three digits does not affect the execution time, it is preferable to the use of the maximum number of digits.

On analysis of the different options related to mutation and crossover modes, with the results compiled in Figures 5-c and 5-d, we observed that all generations above the $25^{\text {th }}$ presented the same (or very similar) optimum values. Regarding the mutation methods, for which the names of the simulations are listed in Table 1, tests 1 and 5 appear to display the most efficient paths in the search for the optimum. With regard to the OF, although all the tests reached nearly the same value, actually the last one result obtained the best value, with a difference in the fifth decimal position.

As presented in Figure 5-e, slightly better results were obtained when elitism was taken into account. This test showed that the optimum was obtained at the $29^{\text {th }}$ generation, whereas it was obtained at generation 47 if elitism was not considered.

Finally, with regard to the number of individuals, as shown in Figure 5-f, all tests reached the same (or very similar) optimum values from the $20^{\text {th }}$ generation onwards, but the test with 25 individuals did not reach an optimum comparable with the others. Simulations with 50,100 and 200 individuals seemed to reach optimum values faster than the others.

Given this analysis, we concluded that from a minimum number of three codification digits and taking elitism into account, most of the other options yielded near optimum 
values by the $30^{\text {th }}$ generation. This implies that, for the particular problem of the Júcar River basin, the search is quite robust regarding the different options considered by the PIKAIA algorithm. It remains to be determined if this holds true for different systems and for different types of ORs.

\section{ANALYSIS OF THE RESULTS AND ASSESSMENT OF TORS}

Once the search parameters of the GA optimisation algorithm were defined, different TORs search possibilities were studied. Among the aspects analysed were different decision curves and restriction values. In all the cases, the decision indicator was considered to be the stored volume at the three main reservoirs.

Three different types of TORs were analysed. First we studied the rule of making a single decision in April and using it until the end of the hydrological year. This TOR has been named "April-September" OR. It is based in the fact that most of the demand is realised between the months of April and September, which coincides with the irrigation period. Moreover, in stream flows are always reduced in the summer. The second proposed rule is a parametric curve using decision variables for only four months and estimating the rest by linear interpolation. It has been named "4 months" OR. Finally, " 12 months" OR is based on the most general case, i.e., making decisions each month of the year. This implies 13 decision variables, taking into account the restriction coefficient as one of them. In all the cases it has been considered a restriction coefficient of the mixed demands double than the one for the traditional demands.

The "April-September" OR is the one that most resembles the current system management because the resource allocation decisions in the Júcar River basin are now made during the meeting of the RWC that takes place at the end of March or the beginning of April. At these meetings, it is decided how much water will be supplied during the coming irrigation campaign. Therefore, attempting to imitate this form of management, the decision variables here are the total stored volume in the month of April and the restriction coefficients of the traditional agricultural demands, with the objective of simultaneously minimizing the one- and ten-year deficits.

For the " 4 months" OR the decision variables were the total stored volume in the reservoirs in October, March, April and September. The selection was based on the fact that October and September correspond to the beginning and the end, respectively, of the hydrological year. April is when the bulk of the irrigation campaign starts, and March falls in between winter and spring. Previous tests using January instead of March yielded slightly worse results. The remaining months were calculated by linear interpolation. Once again, volume and restriction coefficient were the decision variables.

Decision variables of the " 12 months" OR were the volume of each month of the year with a complete possibility of variation between the operational volume and the maximum storage capacity of all three reservoirs. The restriction coefficient was also 
considered to be a decision variable. While in the other TORs the optimisation process lasts a couple of hours, for the " 12 months" OR a simulation with 150 individuals and 1,200 generations took approximately 136 hours (almost 6 days) on an Intel ${ }^{\circledR}$ Core ${ }^{\text {TM }}$ Duo CPU E 7300 running at $2.66 \mathrm{GHz}$. This technique has been applied on a real system whose management is complicated. However, in the case of much bigger systems, the computation time can be very high and therefore constitute a drawback. This is due to the high computational burden involved in GA.

Once the optimisation procedure has been performed for the three possibilities three optimal TORs ("April-September", "4 Months", and "12 Months") were obtained (Figure 6). WRS simulation model was run for each TOR and the results are compared with a situation denoted "basic" OR. The management of the "basic" OR is performed only according to the water distribution order between demands and the water storage order of reservoirs in each month. The order between the demands is imposed by a system of priorities. This rule, commonly called the "blind rule", does not consider saving water for coming months during dry periods. This situation is used as a reference because it essentially represents a blind policy or the option of reactive rather than proactive management.

In Figure 6 it can be seen that the curve for "April-September" was fairly similar to the "4 months" parametric curve. However, the optimisation over twelve months yielded a curve with the highest provision in March instead of April. Moreover, this curve presents a very low value in May. This is because this month has very low effect in the results due to high values of flows in dry years in the month of May. Notice that curves with irregular shapes are not practical and do not inspire confidence. However test of this curve changing the May value presents similar results.

A summary of the results comparing the three TORs and the "basic" simulation can be found in Table 2 and Figures 7 to 9. The evolution of the total stored volume in the three main regulation reservoirs is shown in Figure 7; the stored volume significantly increased with ORs compared with the situation without a rule. However, the volume evolution was almost the same among the scenarios with different rules.

With respect to the maximum deficits occurring in the demands, see Table 2, the reduction of the annual deficits versus the "basic" case was very high for the traditional demands and in the Júcar-Turia Canal. Nevertheless, the two demands from La Mancha worsened the situation due to their pumping possibilities. The results of the maximum ten-year deficit are not as clear as for the annual deficits. Regarding the "basic" OR, the situation was generally worsened for the demands in the zone of La Mancha but improved for the remaining areas. It must be emphasised that the 12-month curve yielded the worst result for this indicator, increasing the deficit for the demands of La Mancha and the Júcar-Turia Canal compared with any other alternative, including the "basic" OR. However, the deterioration of this indicator was expected because the 
proposed OF, and the objective of the TOR, is to diminish the annual deficit; therefore the deficit must be distributed over time.

For example, the demand from the Ribera Alta presents the greatest benefit with any TOR. As presented in Table 2 and Figure 8, which shows the percentages of annual demand, the maximum deficit for one year in the demand of the Ribera Alta dropped from $58 \%$ without an OR to $7-8 \%$ when applying the TORs obtained. Moreover, the ten-year deficit also decreased. The demand of the Ribera Baja reflects the same behaviour.

The irrigation demands from La Mancha, ranging from almost no deficit in their demand to approximately $10 \%$ in the annual deficits and $100 \%$ in the ten-year deficits. This indicates, as it does for the other demands, that the restriction associated with the defined TOR is applied, at least during one month each year. For the demands of La Mancha, these demands worsen slightly their results with respect to the "basic" OR, but getting with this a significant improvement for the demands of the Ribera Alta and Baja, as discussed above.

The demand of the Júcar-Turia Canal made a reduction in the maximum annual deficit by one-half when any of the three TORs was applied, whereas the maximum accumulated deficit for 10 years decreased slightly for the first two TORs defined (April-September and the 4-month parametric curve) and was unaffected by the 12month rule.

Moreover, Figure 9 summarizes the results related to pumping from groundwater in the La Mancha Oriental zones. As observed with all three TORs, the pumped flow was decreased thanks to the imposed restriction with respect the "basic" situation. The mean monthly pumping decreased from 28 to $22 \mathrm{hm}^{3} /$ month, and the maximum went from 95 to $70 \mathrm{hm}^{3} /$ month. The maximum annual pumping changed from 393 to $320 \mathrm{hm}^{3} /$ year, corresponding to a decrease of approximately $20-30 \%$.

Taken together, these results demonstrate that the three TORs are quite similar, justifying, in this case, that it is not necessary to define very complex rules; i.e., decisions made in April and applied for the rest of the irrigation campaign are sufficient to achieve the objective of minimizing the annual and ten-year deficits.

Finally, Figure 10-a shows the three-dimensional evolution of the two decision variables (total volume and the restriction coefficients of the traditional demands) versus the $\mathrm{OF}$ with the results obtained using PIKAIA. This particular case corresponds to the "April-September" OR. Notice that the OF axis represents values of opposite sign; i.e., values near 1 correspond to the best results. Here, the maximum and minimum imposed volumes are 2,000 and $75 \mathrm{hm}^{3}$, respectively. In the cases where the restriction coefficients for the traditional demands are between 0 and 50\%, the solutions tend to cluster near a restriction of $10 \%$. Therefore, it adopts a profile with a marked gradient towards this value, which is maintained as the optimal restriction value for any volume. Figure 10-b, illustrates the relationship between the two decision variables, i.e., volume versus restriction coefficient. Here, it can be seen how the best results are grouped in the 
vicinity of volumes above $1,000 \mathrm{hm}^{3}$ and restriction values between 5 and $15 \%$. Simultaneously, a narrower band is observed near the same restriction values for volumes below $1,000 \mathrm{hm}^{3}$.

The remaining space is filled with dispersed points, indicating that the algorithm searched for combinations over the entire solution space. Figure 10-c plots the evolution of the volume versus the OF. Unlike in the previous case, the two zones in this space contain no points because, for these volumes and for any of their combinations with the restriction coefficient, specific values of the OF were not reached. In this case, the highest concentration of points was reached for a value of the OF of 0.6, corresponding to volumes over $1,000 \mathrm{hm}^{3}$. The most interesting result is the minimum volume for which the maximum value of the OF is reached, which is approximately $1,000 \mathrm{hm}^{3}$. We also observed that it is impossible to obtain values of the OF above 0.2 or below -0.2 with volume values lower than $400 \mathrm{hm}^{3}$. Finally, Figure 10-d shows the other decision variable, the restriction coefficient, versus the OF. This figure is the one with the most number of blank spaces, implying that the OF is highly related to the restriction applied. The greatest concentration of points is near a restriction of 5 to $20 \%$ and a value above 0.2 for the OF. The maximum value of the OF is achieved with a restriction coefficient of approximately $11 \%$ (10.7\%, as stated previously). The blank spaces indicate that, for example, for a restriction of $25 \%$, it is impossible to find a combination with any storage value that yields a value of the OF less than zero.

\section{CONCLUSIONS}

This study presents a new approach for obtaining TORs in a real and very complex WRS. This approach has been applied to the Jucar Basin System. The main problem of the basin is water allocation between the agricultural demands during periods of drought.

The approach proposed is based on the coupling of GAs with NFO based basin simulation models. This has allowed obtaining optimal decision rule curves for water allocation among various demands in periods of scarcity. The GA chosen was PIKAIA, used previously in the optimisation of water quality model parameters. The basin simulation model was developed in the AQUATOOL DSS environment using the SIMGES program, which uses NFO as a tool for river basin water allocation simulations. The problem addressed had the objective of reducing the weighted sum of the maximum annual deficits and the maximum accumulated deficits in the long term. Each evaluation of the OF implies a run of the simulation model with a new TOR and the estimation of the deficit of the demands.

Prior to the application of the approach, several tests were run to define the most suitable parameters for the GA. Next, three possible TORs were analysed, each based on different periods for decision making and application. For the case of the Júcar River, it was concluded that it is sufficient to make a decision in the month of April and apply it from then until September, using a restriction coefficient of $10.7 \%$ for surface water supply when the total volume stored at the three regulation reservoirs falls below 
$1,125 \mathrm{hm}^{3}$. This demonstrates that, in some cases, simple ORs can be used for the management of very complex WRSs.

Acknowledgements The authors wish to thank to the Confederación Hidrográfica del Júcar (Spanish Ministry of the Environment) for the data provided in developing this study and the Spanish Ministry of Science and Innovation (Comisión Interministerial de Ciencia y Tecnología, CICYT) for funding the projects INTEGRAME (contract CGL2009-11798) and SCARCE (program Consolider-Ingenio 2010, project CSD200900065). The authors also thank the European Commission (Directorate-General for Research and Innovation) for funding the project DROUGHT-R\&SPI (program FP7ENV-2011, project 282769) and Seventh Framework Programme of the European Commission for funding the project SIRIUS (FP7-SPACE-2010-1, project 262902). And last, but not least, to the reviewers for their valuable comments, which have improved this paper.

\section{References}

Ahmed, J.A. and Sarma, A.K., 2005 Genetic algorithm for optimal operating policy of a multipurpose reservoir. Water Resources Management 19, 145-161.

$>\quad$ Andreu, J. and Sahuquillo, A., 1987 Efficient aquifer simulation in complex systems, Journal of Water Resources Planning and Management, 113(1), 110-129.

Andreu, J., Capilla, J. and Sanchís, E., 1996 AQUATOOL: A generalized decision support-system for water-resources planning and operational management Journal of Hydrology 177, 269-291.

> Cañon J., González J. and Valdés J., 2009 Reservoir operation and water allocation to mitigate drought effects in crops: a multilevel optimization using the drought frequency index. Journal of Water Resources Planning and Management 135(6):458-465.

$>\quad$ Celeste, A. B. and Billib, M., 2009 Evaluation of stochastic reservoir operation optimization models. Advances in Water Resources 32, 1429-1443.

Chang F.J., Chen L. and Chang L., 2005 Optimizing the reservoir operating rule curves by genetic algorithms. Hydrological Processes 19:2277-2289.

B Bhaskar, N.R. and Whitlach, Jr. E. E., 1980 Deriving of monthly reservoir release policies Water Resources Research 16 (6), 987-993.

$>\quad$ Cai, X., McKinney, D. C. and Lasdon, L. S., 2001 Solving nonlinear water management models using a combined genetic algorithm and linear programming approach Advances in water Reseources 24, 667-676.

Charbonneau, P. and Knapp, B., 1995 A User's guide to PIKAIA 1.0, NCAR Technical Note 418+IA. Boulder: National Center for Atmospheric Research.

$>\quad$ Chen, L., McPhee, J. and Yeh, W-G., 2007 A diversified multiobjective GA for optimising reservoir rule curves Advances in Water Resources 30, 1082-1093.

$>$ CHJ, 1998. Plan Hidrológico de la Cuenca del Júcar. Confederación Hidrográfica del Júcar. Ministerio de Medio Ambiente. España.

> DICTUC, 2010. Análisis integrado de gestión en Cuenca del Río Copiapó. Informe Técnico (Technical Report). División de Ingeniería Hidráulica y ambiental DICTUC para la Dirección General de Aguas. Chile. 
$>\quad$ Elferchichi, A., Gharsallah, O., Nouri, I., Lebdi, F. and Lamaddalena, N., 2009 The genetic algorithm approach for identifying the optimal operation of a multi-reservoir on-demand irrigation system Biosystems Engineering 102, 334-344.

$>\quad$ Efstratiadis, A., Koutsoyiannis, D. and Xenos, D., 2004 Minimising water cost in the water resource management of Athens, Urban Water Journal, 1(1), 3-15.

Ford, C. R. and Fulkerson, D. R., 1962 Flow in networks Princeton University Press. Princeton NJ, 194.

$>\quad$ GPEASAS, 2005 Guía Para La Redacción De Planes Especiales De Actuación En Situación De Alerta Y Eventual Sequía. Ministerio de Medio Ambiente. Dirección General del Agua.

Hsu, S.Y., Tung, C. P., Chen, C.J. and Wang, C., 2004 Application to reservoir operation rule-curves. Proc of world water and environmental resources congress 2004. ASCE Conference Proc 138:304-314.

$>$ IPH, 2008. Instrucción de Planificación Hidrológica. Ministerio de Medio ambiente Rural y Marino, BOE 229 de 22/09/2008.

$>\quad$ Jamieson, D.G., 1997 Special Issue on Decision-Support Systems (DSS). Journal of Hydrology. Vol 177, Nos. 3-4.

$>\quad$ Karamouz, M., Szidarousky, F. and Zahraire, B., 2000 Water Resources system Analysis Lewis Publishers CRC Press Boca Raton Florida, 579.

$>\quad$ Koutsoyiannis, D. and A. Economou., 2003 Evaluation of the parameterizationsimulationoptimization approach for the control of reservoir systems, Water Resources Research, 39 (6), 1170, doi:10.1029/2003WR002148.

$>\quad$ Kuczera, G., 1989 Fast Multireservoir Mulltiperiod Linear Programming Models. Water Resources Research 25:169- 176.

$>\quad$ Kuczera, G., 1993 Network linear programming codes for water-supply headworks modeling. Journal of Water Resources Planning and Management 119:412417.

$>\quad$ Labadie, J., 2004 Optimal Operation of Multireservoirs Systems: State-of-the-Art Review Journal of Water Resources Planning and Management 130 N2 March 1.

$>\quad$ Loucks, D.P. and Sigvaldason, O. T., 1982 Multiple reservoir operation in North America In The Operation of Multiple Reservoir Systems Edited by Z. Kaczmarck and J. Kindler IIASA Collab Proc Ser CP-82-53, 1-103.

$>\quad$ Lund, J. and Ferreira, L., 1996 Operating rule optimisation for Missouri River reservoir system Journal of Water Resources Planning and Management 122 (4), 287295.

$>$ MIMAM, 2000. Libro Blanco del Agua en España. Ministerio de Medio Ambiente. Dirección General de Obras Hidráulicas y calidad de las Aguas. España.

$>\quad$ Mousavi, S. J., Mahdizadehb, K. and Afsharc, A., 2004 A stochastic dynamic programming model with fuzzy storage states for reservoir operations. Advances Water Resources, 1005-1110.

$>\quad$ Nalbantis, I. and Koutsoyiannis, D., 1997 A parametric rule for planning and management of multiple -reservoir systems. Water Resources Research 33, 2165-2177.

$>\quad$ Nicklow, J., Reed, P., Savic, D., Harrell, L., Chan-Hilton, A., Karamouz, M., Minsker, B., Ostfeld, A., Singh, A. and Zechman, E., 2010 State of the art for genetic algorithms and beyond in water resources planning and management Journal of Water Resources Planning and Management 136 (4), 412-432.

Oliveira, R. and Loucks, D. P., 1997 Operating rules for multiresservoir systems. Water Resources Research 33 (4), 839-852. 
Pelletier, P. J., Chapra, S. C. and Tao, K., 2006 Qual2Kw - A framework for modeling water quality in streams and rivers using a genetic algorithm for calibration Environmental Modelling and Software 21, 419-465.

$>\quad$ Rani, D. and Moreira, M., 2010 Simulation-optimization modeling: a survey and potential application in reservoir systems operation. Water Resources Management 24:1107-1138.

Reca, J., Roldán, J., Alcaide, M., López, R. and Camacho, E. 2001a Optimisation model for water allocation in deficit irrigation systems I. Description of the model. Agricultural Water Management 48:103-116.

Reca, J., Roldán, J., Alcaide, M., López, R. and Camacho, E. 2001b Optimisation model for water allocation in deficit irrigation systems II. Application to the Bembézar irrigation system. Agricultural Water Management 48:117-132.

$>\quad$ ReVelle, C., 1999 Optimizing reservoir resources : including a new model for reservoir reliability. New York. John Wiley \& Sons cop.

$>\quad$ Rossi, G., Caporali, A. and Garrote L., 2011. Definition of risk indicators for reservoirs management optimization. Water Resources Management 26:981-996. DOI 10.1007/s11269-011-9842-X.

Sechi, G. M. and Sulis, A., 2009 Water system management through a mixed optimization-simulation approach, Journal of Water Resources Planning and Management, 135(3), 160-170.

Tilmanta, A., Faouzib, E. H. and Vanclooster, M., 2002 Optimal operation of multipurpose reservoirs using flexible stochastic dynamic programming. Applied Soft Computing. Volume 2, Issue 1, 61-74.

$>\quad$ UNICA, 2012 Decision support system models development for multi-use water resource systems in water scarcity conditions using mixed simulation-optimization techniques. Technical Report. University of Cagliari. Italy.

$>\quad$ Wurbs, R., 1993 Reservoir-system simulation and optimisation models Journal of Water Resources Planning and Management 119 (4), 455-472.

$>\quad$ Yamout, G. and El-Fadel, M., 2005 An optimization approach for multi-sectoral water supply management in the greater Beirut area. Water Resources Management 19:791-812.

Yeh, W., 1985 Reservoir management and operations models: A stateof-the-art review Water Resources Research 21 (12), 1797-1818.

$>\quad$ Young, G., 1967 Finding reservoir operating rules Journal of the Hydraulic Division, ASCE 93 (6), 297-321.

$>\quad$ Zoltay, V., Vogel, R., Kirshen, P. and Westphal, K., 2010 Integrated watershed management modeling: generic optimization model applied to the Ipswich river basin. Journal of Water Resources Planning and Management 136:566-575. 


\begin{tabular}{|l|l|}
\hline Code & Explanation \\
\hline 1PMyTIABA & one-point, adjustable rate based on fitness \\
\hline 1PMyTIF & one-point mutation, fixed rate \\
\hline 1PMyTIABD & one-point, adjustable rate based on distance \\
\hline 1PM+RyTIF & one-point+creep, fixed rate \\
\hline 1PM+RyTIABA & one-point+creep, adjustable rate based on fitness \\
\hline 1PM+RyTIABD & one-point+creep, adjustable rate based on distance \\
\hline
\end{tabular}

Table 1. Explanation of different simulations developed to define GA-parameters.

\begin{tabular}{|c|c|c|c|c|c|}
\hline O.R. & $\begin{array}{l}\text { Restriction } \\
\text { Coefficient }\end{array}$ & O.F. & $\begin{array}{l}\text { Deficits (\% of } \\
\text { annual Demand) }\end{array}$ & $\begin{array}{c}\text { Traditional } \\
\text { demands }\end{array}$ & $\begin{array}{c}\text { Mixed } \\
\text { Demands }\end{array}$ \\
\hline \multirow{2}{*}{ Basic } & \multirow{2}{*}{ - } & \multirow{2}{*}{-0.2142959} & MaxDef1year & $40.84 \%$ & $34.90 \%$ \\
\hline & & & MaxDef10years & $72.35 \%$ & $102.34 \%$ \\
\hline \multirow{2}{*}{ April-Sept } & \multirow{2}{*}{0.107} & \multirow{2}{*}{-0.574765} & MaxDeflyear & $9.37 \%$ & $22.20 \%$ \\
\hline & & & MaxDef10years & $90.10 \%$ & $139.13 \%$ \\
\hline \multirow{2}{*}{4 months } & \multirow{2}{*}{0.108} & \multirow{2}{*}{-0.571780} & MaxDeflyear & $9.43 \%$ & $22.27 \%$ \\
\hline & & & MaxDef10years & $90.76 \%$ & $140.09 \%$ \\
\hline \multirow{2}{*}{12 months } & \multirow{2}{*}{0.116} & \multirow{2}{*}{-0.576786} & MaxDef1year & $9.31 \%$ & $23.51 \%$ \\
\hline & & & MaxDef10years & $89.72 \%$ & $154.01 \%$ \\
\hline
\end{tabular}

Table 2. Maximum Deficits for 1 year and 10 years accumulated for the irrigation demands obtained from the simulation model testing optimized ORs. Deficits are in \% of annual demand. 


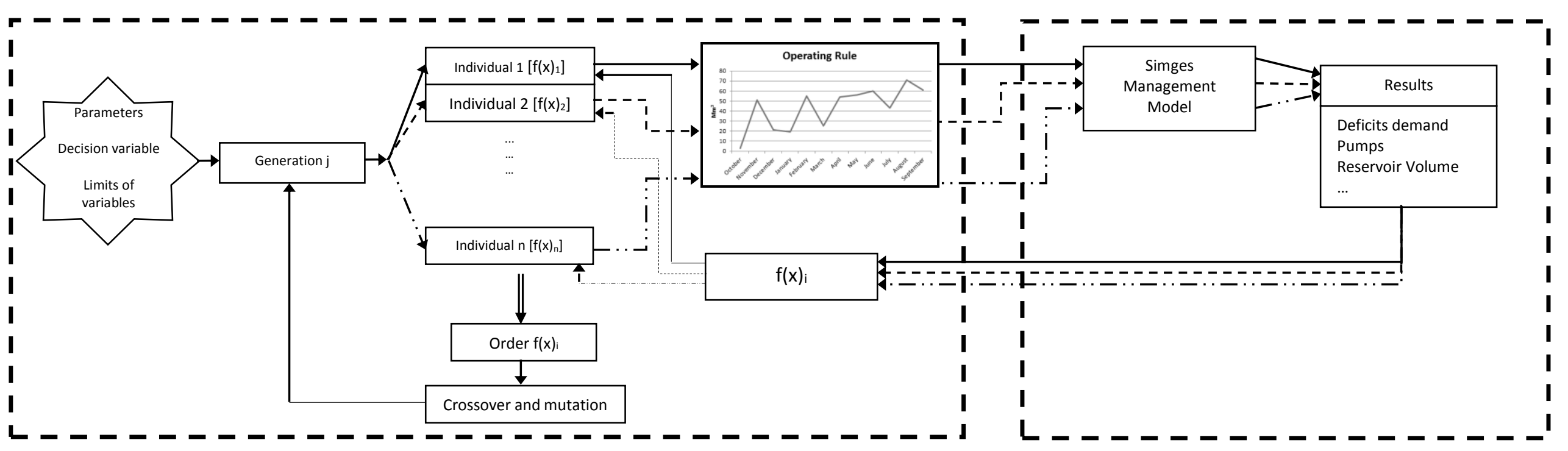

Figure 1. Scheme of the methodological approach applied for the coupling of Pikaia GA and SIMGES water management simulation model. 


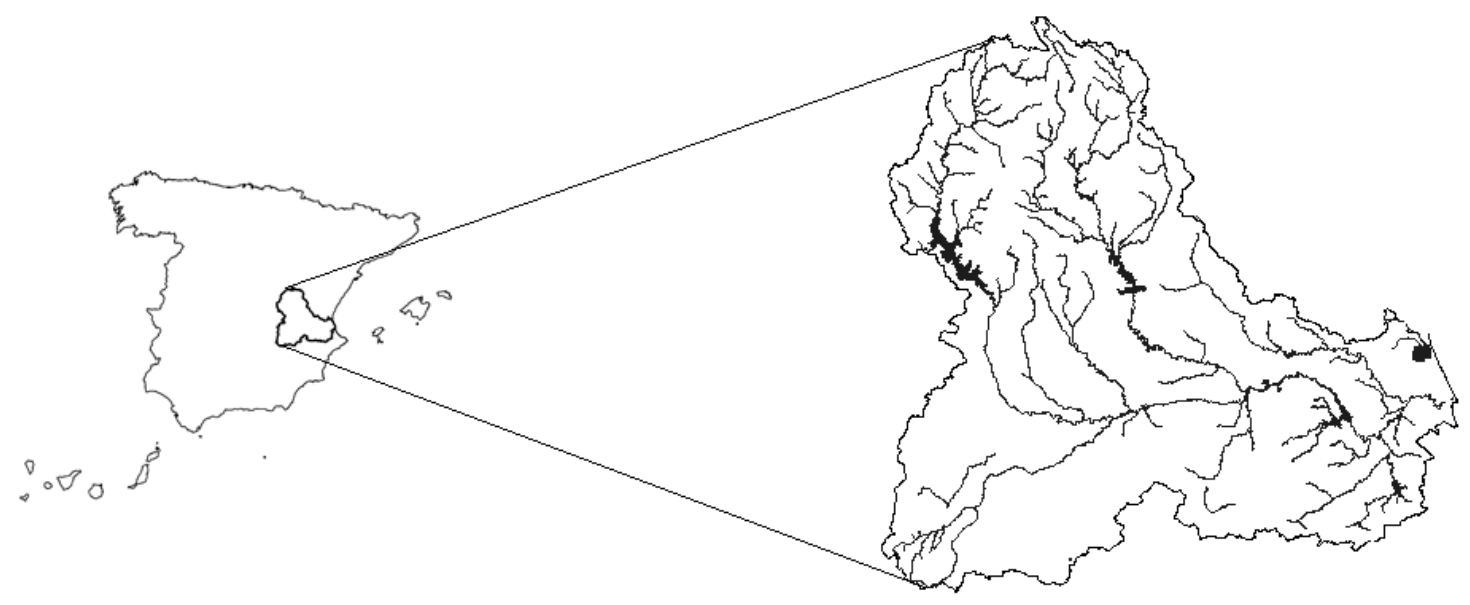

Figure 2. Location of the Júcar River Basin.

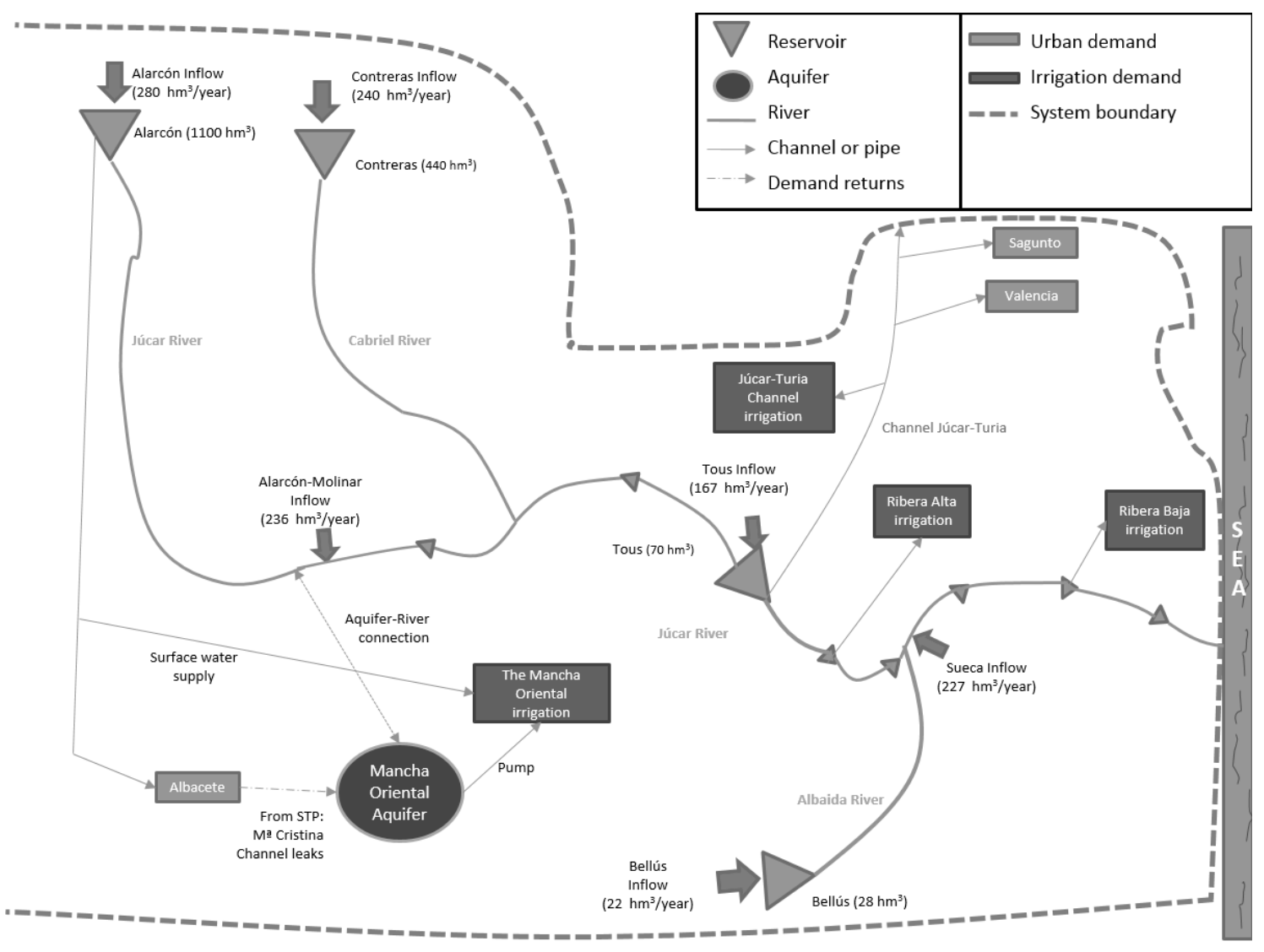

Figure 3. Simplified scheme of the Júcar Water Resources System. 


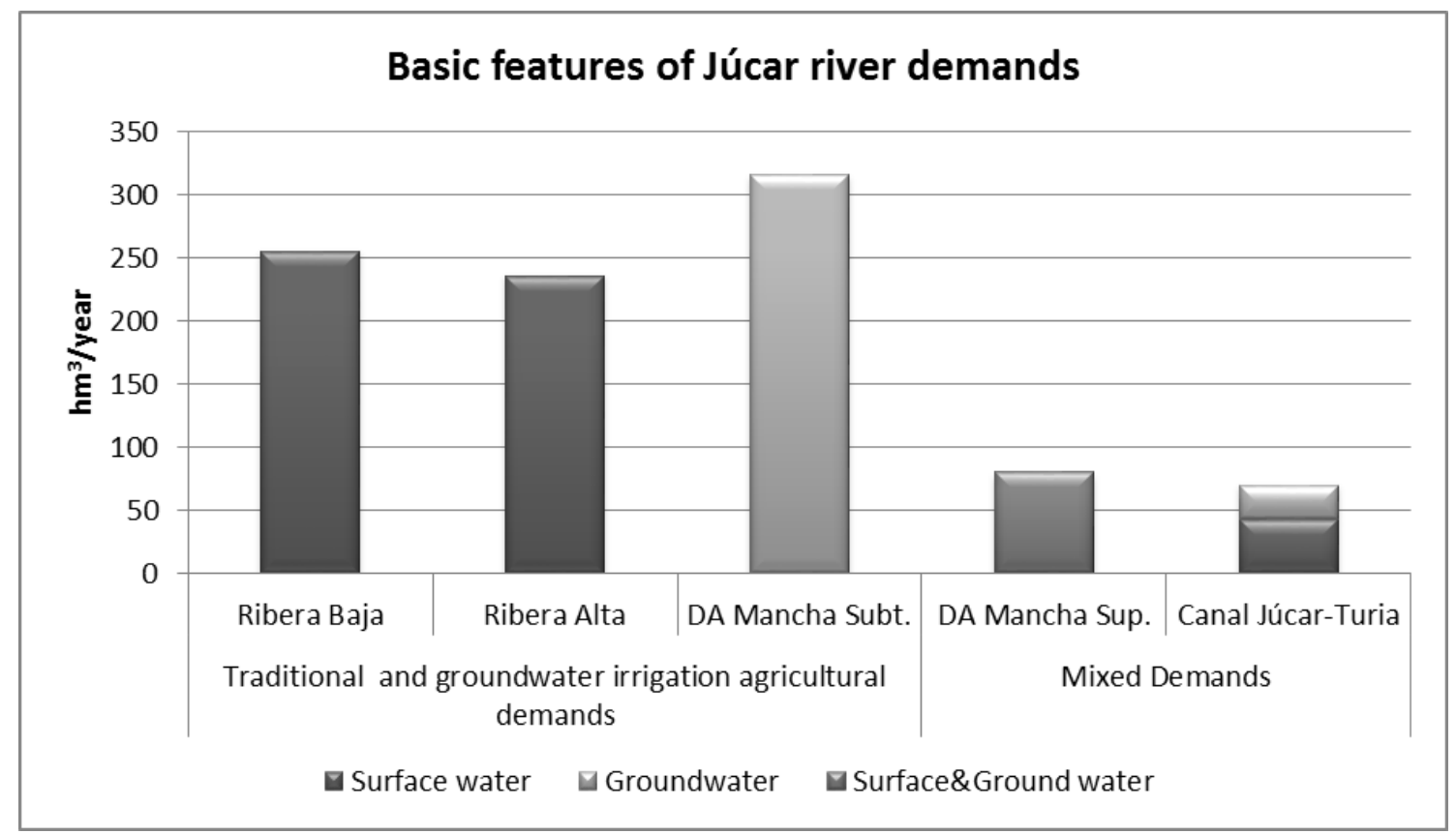

Figure 4. Basic features of Júcar river basin demands. 

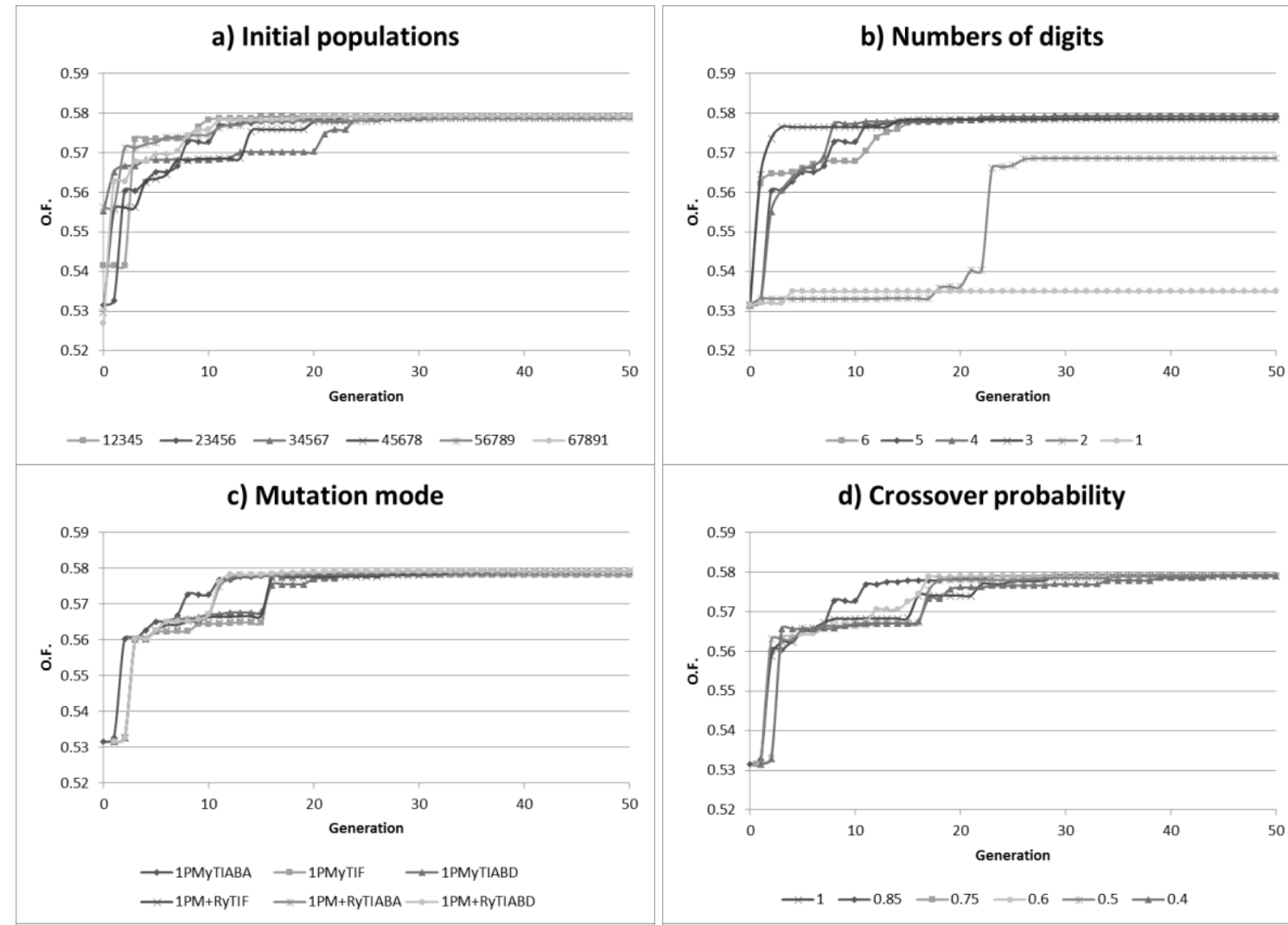

d) Crossover probability

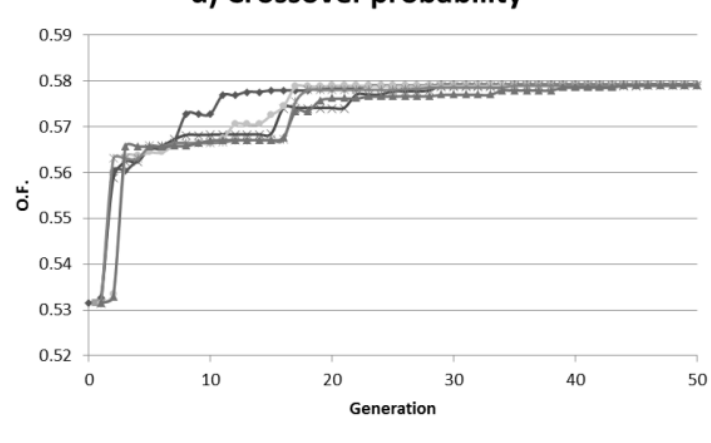

e) Elitism
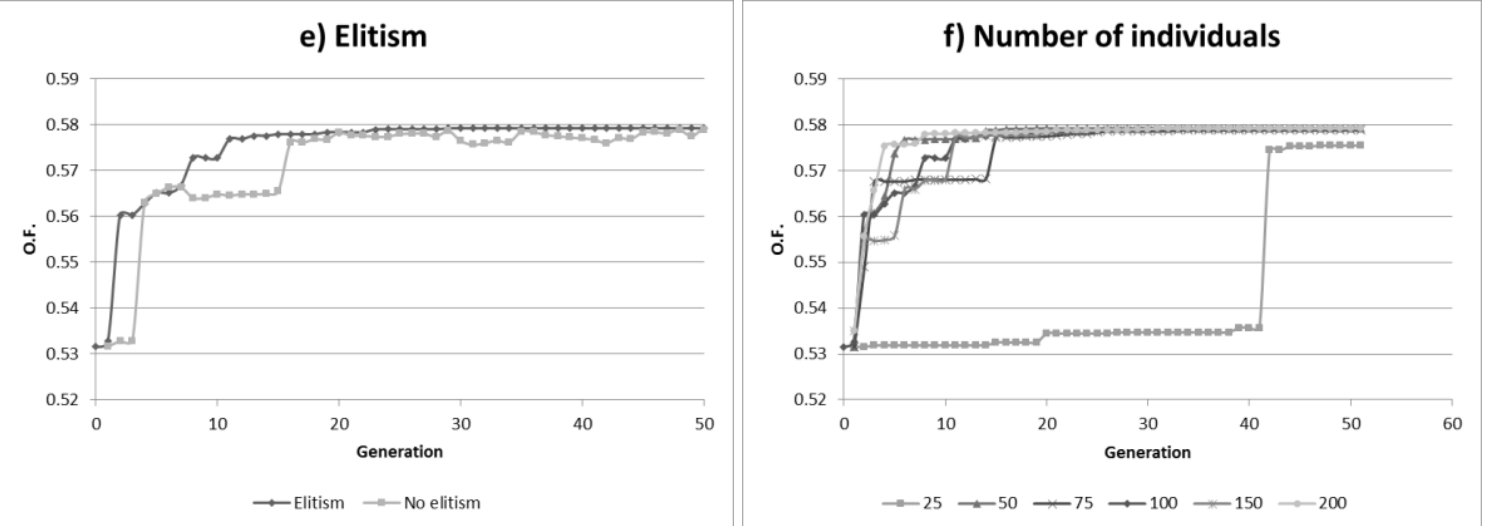

Figures 5 a-f. Results of the Objective Function for different test developed for definition of the GA-parameters. 
Figure 6. Definition of the three ORs obtained from optimisation process.

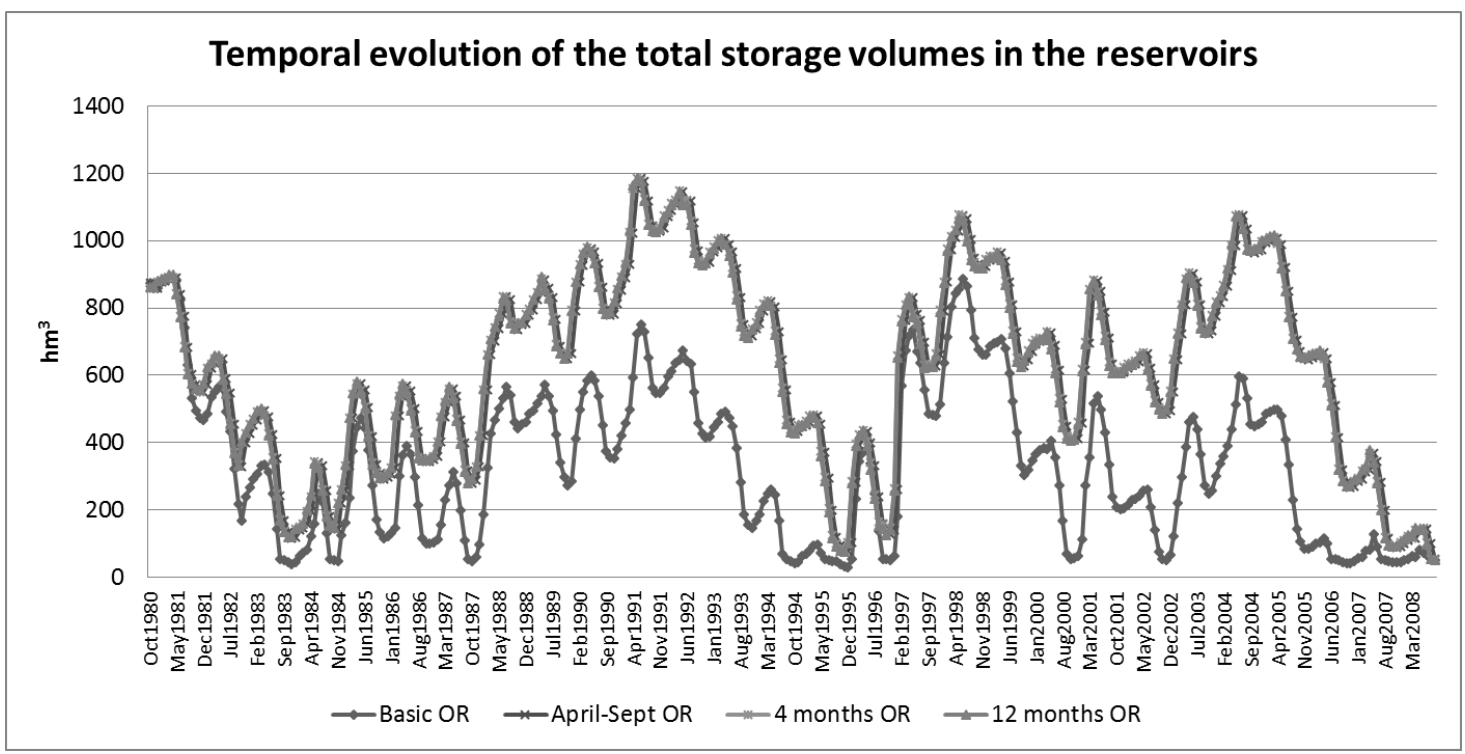

Figure 7. Temporal evolution of total volume stored in the three reservoirs (Alarcón, Contreras and Tous) for the optimized ORs and the "basic" OR.

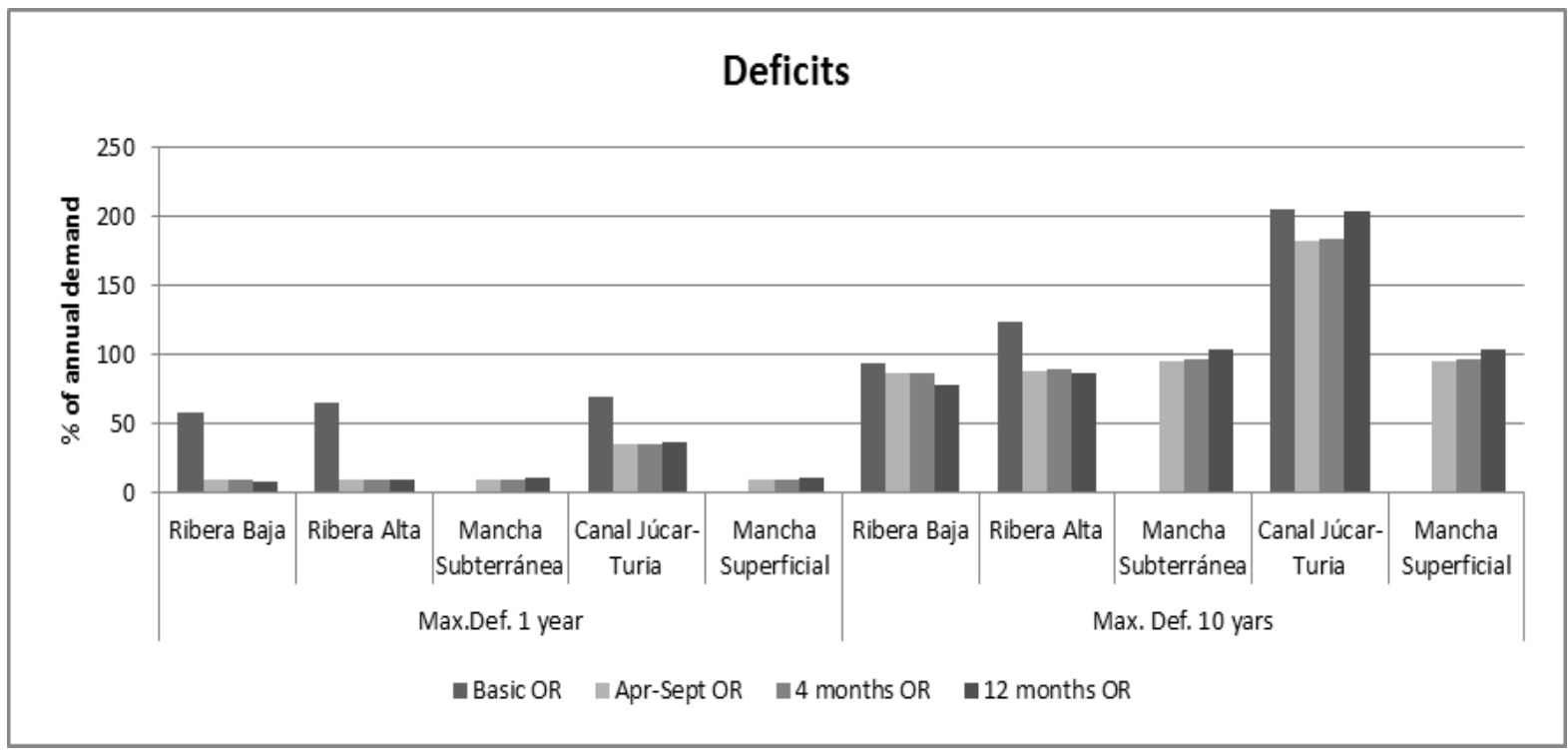

Figure 8. Agricultural demands Deficits obtained from the simulations of the different optimized ORs. Deficits are in \% of annual demand. 


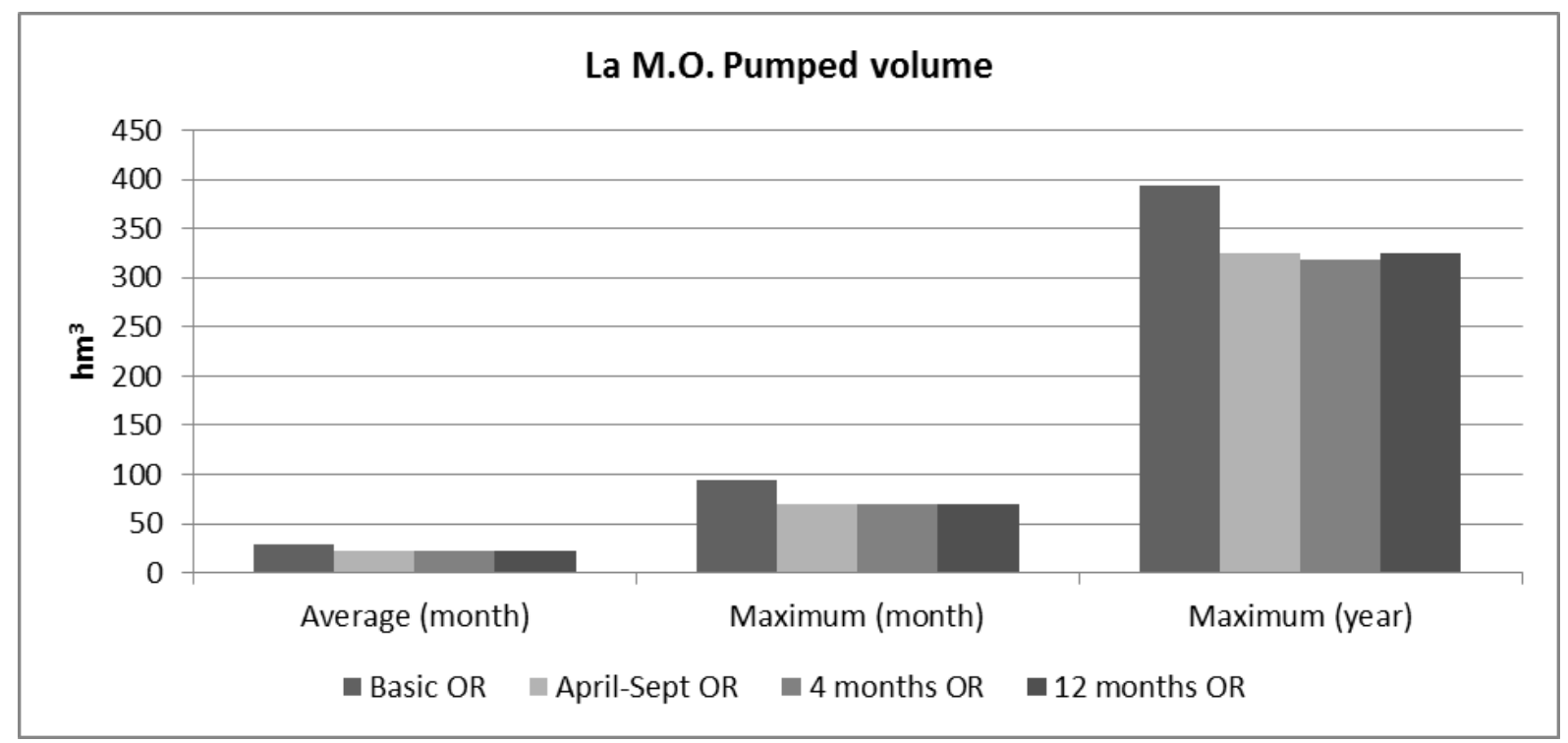

Figure 9. Results for the groundwater abstraction in M. Oriental aquifer for the different optimized ORs. 